\title{
National Health Policy Leadership Program for General Internists
}

\author{
Kelly A. Kyanko, MD, $M H S^{\top}$ (D, Molly A. Fisher, $M D, M S^{2}$, Latonya Riddle-Jones, $M D, M P H^{3}$, \\ Anders Chen, $M D, M H S^{4}$, Francine Jetton, $M A, C A E^{5}$, Thomas Staiger, $M D^{4}$, and \\ Mark D. Schwartz, MD
}

'Department of Population Health, NYU Grossman School of Medicine, New York, NY, USA; ${ }^{2}$ Academic Internal Medicine, Medicine Institute, Allegheny Health Network, Pittsburgh, PA, USA; ${ }^{3}$ Department of Internal Medicine, Wayne State University School of Medicine, Detroit, MI, USA; ${ }^{4}$ Department of Internal Medicine, University of Washington School of Medicine, Seattle, WA, USA; ${ }^{5}$ Society of General Internal Medicine, Alexandria, VA, USA.

INTRODUCTION: Early or mid-career physicians have few opportunities to participate in career development programs in health policy and advocacy with experiential and mentored training that can be incorporated into their busy lives.

AIM: The Society of General Internal Medicine (SGIM) created the Leadership in Health Policy (LEAHP) program, a year-long career development program, to prepare participants with a sufficient depth of knowledge, skills, attitudes, and behaviors to continue to build mastery and effectiveness as leaders, advocates, and educators in health policy. We sought to evaluate the program's impact on participants' self-efficacy in the core skills targeted in the curriculum.

SETTING/PARTICIPANTS: Fifty-five junior faculty and trainees across three scholar cohorts from 2017 to 2021 . PROGRAM DESCRIPTION: Activities included workshops and exercises at an annual meeting, one-on-one mentorship, monthly webinars and journal clubs, interaction with policy makers, and completion of capstone projects.

PROGRAM EVALUATION: Self-administered, electronic surveys conducted before and following the year-long program showed a significant improvement in mean selfefficacy scores for the total score and for each of the six domains in general knowledge, teaching, research, and advocacy in health policy. Compared to the baseline scores, after the program the total mean score increased from 3.1 to 4.1 , an increase of 1.1 points on a 5-point Likert scale (95\% CI: 0.9-1.3; Cohen's D: 1.7), with $61.4 \%$ of respondents increasing their mean score by at least 1 point. Responses to open-ended questions indicated that the program met scholars' stated needs to improve their knowledge base in health policy and advocacy skills. DISCUSSION: The LEAHP program provides an opportunity for mentored, experiential training in health policy and advocacy, can build the knowledge and amplify the scale of physicians engaged in health policy, and help move physicians from individual patient advocacy in the clinic to that of populations.

Prior Presentations: None

Received October 11, 2021

Accepted February 3, 2022

Published online February 23, 2022
KEY WORDS: health policy; training program.

J Gen Intern Med 37(16):4137-43

DOI: $10.1007 / \mathrm{s} 11606-022-07455-\mathrm{y}$

(C) The Author(s) under exclusive licence to Society of General Internal Medicine 2022

\section{INTRODUCTION}

Physicians are uniquely positioned to see and shape how policy affects patient outcomes. However, most have not had sufficient training and experience in health policy and advocacy to be optimally effective in this vital role. ${ }^{1,2}$ The American Board of Internal Medicine, American College of Physicians, and American Medical Association, among other organizations, have called for a commitment to advocacy from every physician. ${ }^{3-5}$ The Accreditation Council for Graduate Medical Education has recently introduced health policy and advocacy requirements across all specialties. ${ }^{6,7}$

Some medical schools have created curricula to teach health policy and advocacy, and recent reviews have described these programs at the undergraduate medical education (UME) and graduate medical education (GME) level. ${ }^{1,8-11}$ However, these curricula are largely focused on basic health policy knowledge and advocacy skills. With the exception of a few programs, ${ }^{12-15}$ they do not include experiential or mentored training which is vital for promoting ongoing engagement and leadership in policy and advocacy. Fellowship programs with experiential work often require physical relocation. ${ }^{16-18}$ Early or mid-career physicians thus have few opportunities to participate in career development programs in health policy and advocacy that can be incorporated into their busy lives.

The Society of General Internal Medicine (SGIM) sought to fill this gap in 2017 by creating the Leadership in Health Policy (LEAHP) program, a year-long career development program, to train physicians to become effective and active health policy advocates, experts, and educators. ${ }^{19}$ Since then, other professional societies have launched similar programs. ${ }^{20}$ To date, no such programs have been described and evaluated in the peer-reviewed literature. In this paper, we describe the LEAHP program and evaluate its impact on meeting the stated 
needs and the self-efficacy of program graduates of the first three cohorts.

\section{METHODS}

\section{Setting and Program Aims}

SGIM is a professional society for more than 3000 academic general internists, whose mission is to cultivate innovative educators, researchers, and clinicians in academic general internal medicine, leading the way to better health for everyone. ${ }^{21}$ The LEAHP program was designed to fill a gap within our society for career development in health policy and advocacy. The program's aims are (1) to develop general internists who will become effective and active health policy advocates and local health policy experts, leaders, and teachers; (2) to offer health policy career development resources and opportunities to all SGIM members; and (3) to develop an expanding, national cadre of SGIM members who can broaden engagement in the Society's health policy efforts.

\section{Program Description}

The program aims to prepare participants with a sufficient depth of knowledge, skills, attitudes, and behaviors to continue to build mastery and effectiveness as leaders, advocates, and educators in health policy. ${ }^{22-24}$ The LEAHP program aspires to focus on facts, evidence, and approaches with respect for the breadth and diversity of policy opinions and perspectives of all its participants. SGIM members with an interest in health policy were encouraged to apply each fall to be LEAHP scholars. The ongoing program was offered to three cohorts of scholars to date, 2017-2018, 2018-2019, and 2020-2021. The 2019-2020 year was skipped during a strategic planning year for SGIM, after which the LEAHP program restarted in the 2020-2021 year.

Table 1 Major Domains and Learning Objectives of the Leadership in Health Policy Program

Scale domain and learning objectives (Cronbach's alpha coefficient for domain scales, $N=54$ )

General (0.90)

- Describe the key structures and functions of the American healthcare system

- Describe the federal health policy apparatus - key institutions and leaders

- Explain the key decision-makers and timeline of the federal budgeting process

- Explain the distinctions between authorization and appropriation legislation

- Define the distinctions between mandatory and discretionary spending

- Compare various healthcare cost control strategies

- Describe at least 10 of the Affordable Care Act's (ACA) key provisions

- Note 3 current problems in the ACA that would require legislative action

- Explain the rulemaking process - how policy is implemented and regulated

- Describe the variability in how health policy is implemented across the states

- Name at least 5 key moments in the history of American health policy

Clinical practice $(0.73)$

- Explain how healthcare systems shape variation in outcomes

- Describe the basics of how healthcare is financed by public and private payers

- Describe how the Medicare Access and CHIP Reauthorization Act of 2015 (MACRA) is reshaping physician payment policy

- Explain the rules driving the Alternate Payment Model and Merit-based Incentive Payment System provisions in MACRA

- Compare various "value-based" clinician payment policies and how each differs from prior payment policies

- Describe how the Centers for Medicare and Medicaid Services (CMS) develops and implements the physician fee schedule

- Explain the deficiencies and consequences of the regulations regarding Evaluation and Management coding

- Describe strategies for promoting quality measures and incentives

Education (0.78)

- Explain how Medicare policy shapes graduate medical education (GME) financing and programs

- Describe the ongoing debate on how to reform GME financing

- Explain how federal policy impacts the health professional workforce

- Describe the historical context of Title 7 programs and how it has evolved

- Describe how public GME funding contributes to the financial viability of academic medical centers

Research (0.82)

- Describe how the appropriations process shapes research priorities

- Explain how the missions and priorities of PCORI and AHRQ compare

- Describe the major executive branch agencies with authority over research

- Provide examples of how federal regulations impact research priorities

Advocacy (0.92)

- Compare strategies and challenges of advocacy at the state level compared with the federal level

- How to prepare leave-behind materials for advocacy visits

- How to optimize talking points for advocacy visits

- Effective communication strategies with policy makers

- Describe the mission and health policy priorities of other professional societies

- Explain how to build and leverage coalitions in health policy advocacy

- Describe how administrative advocacy differs from legislative advocacy

Teaching health policy $(0.91)$

- Design a curriculum on health policy for medical students or residents

- Prepare a lecture on the strengths and limitations of the ACA

- Integrate health policy education into teaching that I already do

- Lead a journal club on an article about a health policy topic 
In collaboration with senior SGIM faculty with extensive health policy expertise, we developed a set of learning objectives in several domains to drive the design of the program. Core domains included general foundational concepts of the American healthcare system, how policy and health systems influence variation in clinical outcomes, graduate medical education financing and programs, the federal appropriations process for research, strategies and tactics for state and federal advocacy, and teaching health policy to others (Table 1). The overall elements of the program are described below and illustrated in Figure 1. An online table was used to track scholar participation in learning activities.

After several weeks of required reading, the program began each spring at the SGIM annual meeting. In a half-day series of workshops and exercises, scholars were taught the basic anatomy and physiology of the federal health policy apparatus, and how to apply these foundational concepts to policies related to the core missions of the Society, particularly those that drive education, research, and clinical practice for general internists. Scholars participated in at least two other health policy-themed workshops at the annual meeting, in a Health Policy Interest Group, and in one or more of the Health Policy Subcommittee meetings (Clinical Practice, Education, or Research). They had an initial meeting with their program mentor to review their individual development plan for the year. LEAHP scholars were matched with mentors with extensive health policy experience (two scholars per mentor).

Following the annual meeting, scholars participated in monthly, online webinars that alternated between workshops on additional key concepts of health policy and advocacy and health policy journal club discussions led by the scholars. Sample themes of these webinars are listed in Figure 1.
Webinars led by health policy experts were preceded by key background reading assignments. During the journal club sessions, 3-4 scholars shared the tasks of selecting and reviewing an academic paper on a health policy theme, along with articles in the lay media from the liberal and from the conservative perspectives on the issue. Scholars led a discussion of these papers and the policy issue, with additional insights provided by the mentors.

Scholars joined and participated in the work of one of the three Health Policy Subcommittees noted above. The Subcommittees met monthly online to review health policy updates relevant to their focus area from SGIM's government affairs consultants, and to discuss actions and issues in their advocacy agenda.

LEAHP scholars met monthly with their mentor to guide their learning and their choice and completion of at least two capstone projects, designed by the scholars. These could include a commentary or white paper on a policy theme, design and implementation of a health policy educational activity or curriculum, a policy workshop presented at a regional or annual SGIM meeting, an advocacy project with the preparation of leave-behind materials and talking points, op-eds, or another substantive activity with approval of the mentor and program directors. At a mid-year capstone project review, scholars presented their work in progress in small groups facilitated by mentors to discuss accomplishments, challenges, and feedback from the group.

The program culminated at the subsequent annual SGIM meeting with a half-day session of advanced workshops, presentations on their capstone projects, and the opportunity to meet the incoming cohort of LEAHP scholars in the next year's program.
Monthly

Webinars

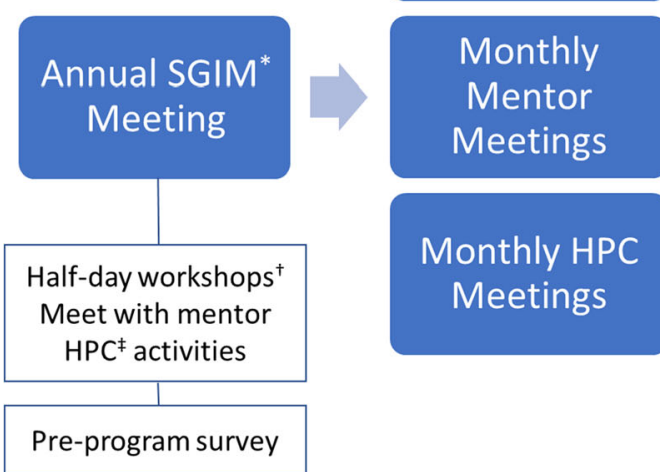

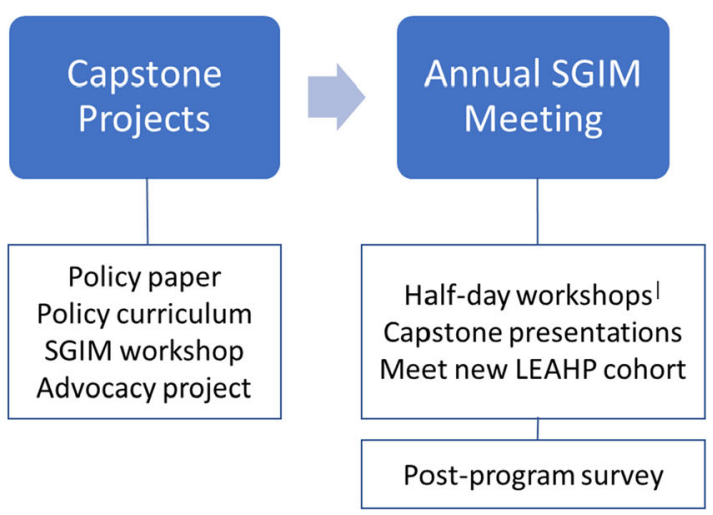

${ }^{*}$ SGIM - Society of General Internal Medicine

${ }^{+}$How health policy is made; Appropriation policy for research; Graduate medical education policy; and Physician payment policy

${ }^{\ddagger}$ HPC (Health Policy Committee) Subcommittee meetings and health policy workshops at Annual Meeting

$\S$ For example: Social determinants of health policy; Research advocacy - Creation of PCORI; Primary care payment reform; Mass incarceration and public health; and Medicaid expansion policy

I Medicaid and state level advocacy; How to organize a coalition; and Little p: local health policy 


\section{Program Evaluation}

We evaluated the LEAHP program and its impact on scholars using self-administered, electronic surveys conducted just before and immediately following the year-long program. The pre-program survey gathered descriptive information about the scholars including their demographics, professional roles, and past experiences engaging in health policy activities. Scholars were also asked the open-ended question, "What are the three things you want to be able to do as a result of this program that you are unable to do now?"

The remaining items used in these surveys were developed based on the program's learning objectives, which were each provided as statements of self-efficacy. For example, "I can describe the key structures and functions of the American healthcare system." Scholars were asked to rate the degree to which they agreed with each statement on a 5-point Likert scale from $1=$ strongly disagreed through $5=$ strongly agreed with $3=$ neutral. The questionnaires had a total of 38 selfefficacy items clustered into six domains, including 10 on general foundations, 4 on clinical practice policy, 4 on education policy, 4 on research policy, 12 on advocacy, and 4 on teaching others about health policy. The same questionnaire items were asked before and after completion of the program.

The post-program questionnaire also included optional open-ended items to assess the perceived impact of the program on the scholars' learning and career, and the most helpful aspects of the program. In addition to a question regarding future plans in health policy, scholars were asked, "Name three things you have learned this year that you think will have enduring value for you" and "What were the most meaningful or helpful elements of the program for you?" The last two cohorts were also asked, "What suggestions do you have for building or strengthening the impact of the program for future cohorts?"

The NYU Grossman School of Medicine Institutional Review Board determined this study was exempt from review.

\section{Analysis}

We conducted scale reliability analysis on the pre-program survey data to calculate the Cronbach alpha coefficient for the set of self-efficacy items within each of the six domains, and to determine each scale's alpha coefficient after each item comprising the scale was removed, one at a time, to assess the reliability of these domain scales. ${ }^{25}$ We calculated mean scores for each domain scale and a total mean score for all items on the pre- and post-program surveys. We used paired samples $t$ tests to compare these mean scores between subjects before and after the program. We calculated Cohen's $D$ for the change in each mean score to estimate the effect size. ${ }^{26} \mathrm{We}$ also determined the percentage of respondents who improved $\geq 1$ point on the 5 -point scale from the pre- to post-program surveys, reflecting a change in response categories (e.g., from "Neutral" to "Agree").
We analyzed open-ended responses to survey questions through an iterative team-based approach. Two coders (KK and LR) independently reviewed and developed initial thematic codes for each question, and then met to resolve discrepancies and refine a unified set of codes that was then shared and discussed with the larger team. We continued to update the codes and their descriptions until no new codes were needed to describe the data. The final codes were applied to the data by one team member (KK) and reviewed by other team members. Consensus was reached through team discussions and sharing of documents and note-taking to record justifications. Scholar responses for each question were split into separate comments as necessary to represent unique thoughts. If a comment fit with more than one code, the code most strongly associated with the text was applied. Few (5\%) comments did not align with the themes and were not coded. We used coded data to identify overarching recurrent themes and calculated the frequency of each theme among all coded comments.

\section{RESULTS}

The first three cohorts included 55 scholars who enrolled in the program. Of these, 54 (98.2\%) completed the pre-program survey, 52 (94.5\%) completed the program (3 enrollees dropped out of the program mid-way), and 44 of the 52 $(84.6 \%)$ completed both the pre- and post-program surveys. As shown in Table 2, about two-thirds of the scholars were female and $14.5 \%$ were underrepresented in medicine (URiM, defined as Black/African American, Hispanic/Latino, American Indians or Alaska Natives, or Native Hawaiians and other Pacific Islanders). Scholars resided in 21 different states and the District of Columbia. Most were faculty in General Internal Medicine, of whom most were assistant professors, and the remainder were trainees (most residents or fellows in GIM).

\section{Self-efficacy in Health Policy}

The questionnaire items in the six thematic domains described above had Cronbach's alpha coefficients for each scale ranging from 0.73 to 0.92 (Table 1). Removal of any of the items from its scale domain reduced the alpha coefficient, so all

Table 2 Characteristics of the LEAHP Program Scholars

\begin{tabular}{llllll}
\hline \hline $\begin{array}{l}\text { Cohort } \\
\text { year }\end{array}$ & $\begin{array}{l}\text { Number } \\
\text { of } \\
\text { scholars }\end{array}$ & $\begin{array}{l}\text { \% } \\
\text { Female }\end{array}$ & $\begin{array}{l}\text { \% } \\
\text { URiM* }\end{array}$ & $\begin{array}{l}\text { \% } \\
\text { Trainees }\end{array}$ & $\begin{array}{l}\text { \% } \\
\text { Faculty }\end{array}$ \\
\hline $2017-$ & 19 & 73.7 & 10.5 & 10.5 & 89.5 \\
2018 & 14 & 71.4 & 14.3 & 21.4 & 78.6 \\
$2018-$ & 14 & 54.5 & 18.2 & 13.6 & 86.4 \\
2019 & 22 & 65.5 & 14.5 & 14.5 & 85.5 \\
$2020-$ & 2021 & 55 & 6 & \\
\hline
\end{tabular}

*Underrepresented in medicine, defined as Black/African American, Hispanic/Latino, American Indians or Alaska Natives, or Native Hawaiians and other Pacific Islanders 
Table 3 Mean Self-efficacy Scores for Each Health Policy Domain Scale Before and After the Program $(N=44)$

\begin{tabular}{|c|c|c|c|c|c|}
\hline $\begin{array}{l}\text { Domain } \\
\text { scale }\end{array}$ & $\begin{array}{l}\text { Pre-program mean } \\
\text { (SD) }\end{array}$ & $\begin{array}{l}\text { Post-program mean } \\
\text { (SD) }\end{array}$ & $\begin{array}{l}\text { Pre-post program mean difference } \\
\text { (95\% CI)* }\end{array}$ & $\begin{array}{l}\text { \% with pre-post mean } \\
\text { change } \geq 1.0\end{array}$ & $\begin{array}{l}\text { Cohen's } \\
D^{\dagger}\end{array}$ \\
\hline General & $2.9(0.7)$ & $4.1(0.5)$ & $1.1(0.9,1.4)$ & 65.9 & 1.5 \\
\hline Practice & $3.3(0.7)$ & $4.2(0.5)$ & $1.0(0.7,1.2)$ & 50.0 & 1.2 \\
\hline Education & $3.0(0.7)$ & $4.1(0.6)$ & $1.2(0.9,1.4)$ & 58.1 & 1.3 \\
\hline Research & $2.3(0.7)$ & $3.8(0.7)$ & $1.4(1.2,1.7)$ & 70.5 & 1.6 \\
\hline Advocacy & $3.4(0.7)$ & $4.4(0.5)$ & $1.0(0.7,1.2)$ & 47.7 & 1.4 \\
\hline Teaching & $3.5(0.9)$ & $4.4(0.6)$ & $0.9(0.7,1.1)$ & 50.0 & 1.0 \\
\hline Total score & $3.1(0.5)$ & $4.1(0.4)$ & $1.1(0.9,1.3)$ & 61.4 & 1.7 \\
\hline
\end{tabular}

Participants rated on a 5-point Likert scale the degree to which they agreed with self-efficacy statements based on the program's learning objectives. For example, "I can describe the key structures and functions of the American healthcare system." $(1=$ Strongly disagree; $2=$ Disagree; $3=$ Neutral; $4=$ Agree; and $5=$ Strongly disagree)

Forty-four participants that completed both the pre-program and the post-program surveys

${ }^{*} p<0.001$ for all comparisons

Effect size for difference between pre-program and post-program means, all large effects

items were used to generate mean scores for each domain and a total score.

The mean self-efficacy scores for each domain scale before and after the program, along with the mean change in scores, are shown in Table 3. Before the program, the overall score was 3.1, approximately neutral on the 5-point scale. Before the program, the highest mean score was for teaching about health policy (3.5), while the lowest was for health policy regarding research issues (2.3). Scores for the pre-program survey were similar for those that responded to the post-program survey and those that did not. Compared to the baseline scores, after the program the total score increased by a mean of 1.1 points (from 3.06 to 4.15 ), with $61.4 \%$ of respondents increasing their mean score by at least 1 point. For each of the six domains, there was a significant and meaningful improvement in mean self-efficacy scores of about 1 point. Policy on research issues improved the most and teaching health policy improved the least. Cohen's $D$ for all comparisons showed large effect sizes, ranging from 1.0 to 1.7. Mean scores and improvement were similar and significant for each of the three cohorts, and were independent of the scholars' gender, minority status, or career stage.

\section{Open-Ended Responses}

Analysis of the open-ended questions revealed the following themes (Table 4). Prior to the LEAHP program, scholars mostly commonly reported that they hoped to gain proficiency in advocacy skills, followed by improving their knowledge base in health policy, becoming better educators and developing curricula, and learning writing skills and output of published products (Table 4, Question 1).

After the program, scholars most frequently expressed that improvements in their advocacy skills and confidence and drive to make change, and in addressing issues of importance to them were of most enduring value. This included a sense of optimism of the ability of physicians to create change and scholars' plans to incorporate policy into their future careers (Table 4, Question 2). Improved understanding on the policy process (e.g., how a bill becomes a law, budgetary appropriations) and a deeper knowledge on how the healthcare system and government interact, understanding of payment and reimbursement, and networking among colleagues were also of enduring value.

Mentorship by both assigned mentors and LEAHP leadership, and collaboration and in-person activities with fellow scholars from other institutions with similar interest in policy and advocacy were noted as most meaningful and helpful aspects of the program (Table 4, Question 3). This was followed by didactics such as capstone projects, lectures, and journal clubs, and actively using learned skills through Hill Day, the annual SGIM advocacy day where participants meet with members of congress, and other interactions with policy makers.

The two most common suggestions for program improvements included more opportunities for connection and collaboration given that most of the activities were virtual even before the COVID-19 pandemic (Table 4, Question 4). Scholars also requested more basic didactics and ways to engage alumni of the program as peer mentors.

\section{DISCUSSION}

We described the objectives, design, and evaluation of SGIM's year-long, national LEAHP program for physician career development in health policy and advocacy. Most participants improved markedly in their general knowledge, teaching, research, and advocacy in health policy. To date, no such health policy career development program has been described and evaluated in the peer-reviewed literature.

Responses to open-ended questions also indicated that the program met scholars' stated needs to improve their knowledge base in health policy and advocacy skills. While didactics such as lectures and journal clubs were helpful to scholars, the most commonly cited meaningful aspects of the program were mentorship and collaboration with colleagues. Incorporating some in-person time into the program (by leveraging the annual meeting) was valuable and the program was feasibly integrated into the schedule of busy physicians. These relationships may be critical for longer term engagement and 
Table 4 Themes Identified in Open-Ended Questions with Representative Quotations

\begin{tabular}{|c|c|c|}
\hline Themes & $\begin{array}{l}\text { Comments exhibiting theme } \\
\text { ( } N, \% \text { of comments)* }\end{array}$ & Representative quote \\
\hline \multicolumn{3}{|c|}{ Q1: What are the three things you want to be able to do as a result of this program that you are unable to do now? $(N=157)$} \\
\hline Advocacy skills & $63(40 \%)$ & $\begin{array}{l}\text { "Improve ability to articulate gaps in our health care system and the improve my } \\
\text { ability to communicate concerns effectively at various levels" }\end{array}$ \\
\hline $\begin{array}{l}\text { Improve knowledge base of } \\
\text { health policy }\end{array}$ & $45(29 \%)$ & "Have a deeper understanding of how health policy is crafted and implemented" \\
\hline Teaching & $32(20 \%)$ & $\begin{array}{l}\text { "Be better and more effective in development and implementation of a health } \\
\text { policy curriculum for undergraduate and postgraduate medical education" }\end{array}$ \\
\hline Publications and writing & $13(8 \%)$ & "Draft policy papers and op-eds explaining and advocating for various positions" \\
\hline \multicolumn{3}{|c|}{ Q2: Name three things you have learned this year that you think will have enduring value for you. $(N=130)$} \\
\hline Physician as advocate & $48(37 \%)$ & $\begin{array}{l}\text { "I have learned, quite tangibly, the power of using my voice (and pen) to advocate } \\
\text { for (or against) policy issues that have a significant impact on the lives of my } \\
\text { patients and community." }\end{array}$ \\
\hline Health policy process & $31(24 \%)$ & $\begin{array}{l}\text { "Much clearer understanding of the process by which a bill is created and becomes } \\
\text { a law. I also now understand where in that process advocacy is possible and } \\
\text { helpful." }\end{array}$ \\
\hline $\begin{array}{l}\text { Payment and } \\
\text { reimbursement }\end{array}$ & $29(22 \%)$ & $\begin{array}{l}\text { "Complexity of our health financing and payment system and how competing } \\
\text { interests impact progress" }\end{array}$ \\
\hline $\begin{array}{l}\text { Networking among } \\
\text { colleagues }\end{array}$ & $15(12 \%)$ & $\begin{array}{l}\text { "Working with my LEAHP cohorts: this was very enjoyable to see others" } \\
\text { speaking skills, interests, etc. Although I have been interested in health policy for } \\
\text { some time, it became more of a "team sport" through interactions with colleagues. } \\
\text { I have learned the value of conference calls, etc. - as silly as that may sound, it is } \\
\text { encouraging to see how cross-institutional work can be realistically completed." }\end{array}$ \\
\hline \multicolumn{3}{|c|}{ Q3: What were the most meaningful or helpful elements of the program for you? $(N=78)$} \\
\hline Mentorship & $22(28 \%)$ & $\begin{array}{l}\text { "The direct mentoring was incredibly valuable in pushing me to think bigger about } \\
\text { what I could achieve" }\end{array}$ \\
\hline $\begin{array}{l}\text { Collaboration with } \\
\text { colleagues }\end{array}$ & $22(28 \%)$ & $\begin{array}{l}\text { "The opportunity to work across institutions on a policy curriculum has been } \\
\text { career-changing for me. Whereas many academic groups tend to become territorial } \\
\text { about collaboration, the LEAHP cohort was united by a common (and very } \\
\text { passionate) desire to develop future leaders in General Internal Medicine through a } \\
\text { standardized curriculum. In addition to the excitement of taking on this big dream } \\
\text { so many of us already seemed to share, I made lifelong friends and colleagues } \\
\text { across the country, with whom I will now (hopefully!) take on future tasks." }\end{array}$ \\
\hline $\begin{array}{l}\text { Didactics and instructional } \\
\text { strategies }\end{array}$ & $19(24 \%)$ & $\begin{array}{l}\text { "The webinars and monthly workshops were very helpful in hearing other's ideas, } \\
\text { critically thinking about policy and broadening knowledge." }\end{array}$ \\
\hline Advocacy in action & $12(15 \%)$ & $\begin{array}{l}\text { "Hill Day was very meaningful. I felt this year much more prepared than the first } \\
\text { time I went." }\end{array}$ \\
\hline \multicolumn{3}{|c|}{ Q4: What suggestions do you have for building or strengthening the impact of the program for future cohorts? $(N=30)^{\dagger}$} \\
\hline $\begin{array}{l}\text { Increase connectivity and } \\
\text { meet-ups }\end{array}$ & $11(37 \%)$ & $\begin{array}{l}\text { "More frequent but less formal times to gather - casual happy hours for a topic or } \\
\text { discussion." }\end{array}$ \\
\hline Collaborative projects & $5(17 \%)$ & $\begin{array}{l}\text { "I know group work is always challenging, but maybe more small group work. I } \\
\text { was involved with three SGIM workshops (which we set up independently with } \\
\text { current LEAHPers and mentors) and the meetings and discussions for those } \\
\text { projects were very helpful. I also think this helped form some lasting bonds for } \\
\text { future work since we all met multiple times to set these projects up." }\end{array}$ \\
\hline More basic didactics & $4(13 \%)$ & $\begin{array}{l}\text { "Would love to have discussion on the basics - review of glossary terms and what } \\
\text { they mean and truly entail." }\end{array}$ \\
\hline Peer mentors & $4(13 \%)$ & $\begin{array}{l}\text { "I think peer mentors would be helpful - making a connection early with someone } \\
\text { who had gone through the program already would be helpful in brainstorming } \\
\text { projects and just collaboration on a broader scale." }\end{array}$ \\
\hline
\end{tabular}

*Percentages do not round to $100 \%$ as a small number of comments did not align with any of the predominant themes and were not coded. Q1: $4 / 157$ (3\%); Q2: 7/130 (5\%); Q3: 3/78 (4\%); Q4: 6/30 (20\%); Total 20/395 (5\%)

${ }^{\dagger}$ Question 4 was completed only by the last two cohorts

career development and building a community of physicians active in health policy.

Previous reports of health policy and advocacy curricula have focused on basic foundational knowledge and skills at the UME and GME levels. SGIM's program is unique in that it targets practicing physicians, focuses on a higher level of training including mentored and experiential work, and does not require physical relocation.

LEAHP graduated its third cohort of scholars and is training its fourth. Several factors promoted its implementation and sustainability. First, the program recruited a committed group of experienced mentors, and most have continued with the program. We learned from the experiences of other SGIM career development programs in education and leadership. ${ }^{27,28}$ The LEAHP program has a dedicated staff partner (FJ) for data management, communications, scheduling, and website management. Recruitment of scholars was aided by the willingness of many scholars to comment on the quality and value of the program in print and in conversations with colleagues. ${ }^{24}$

A limitation of these results is the short-term follow-up. We plan to conduct a longer term follow-up survey to assess the durability of improvements in self-efficacy and the program's impact on career development and accomplishments in health policy. We did not objectively measure knowledge using exam scores, although self-efficacy is predictive of career choice, persistence, and achievement. ${ }^{29}$ Another limitation is 
the lack of an unexposed control group. The cohort of physicians participating in the program represent a self-selected group of academic general internal medicine physicians and trainees, many already engaged in health policy in their own institutions. Application of the program to other physician groups is uncertain, but key concepts reviewed in the program such as advocacy skills like building and leveraging coalitions and communication strategies with policy makers, and core knowledge of the legislative process are likely to apply to most practicing physicians.

To address the scholars' suggestions for improvement, we have added a few evening LEAHP "happy hours"-informal, virtual gatherings to discuss themes driven by scholars, collaborations on capstone projects, and career crafting discussions with mentors and LEAHP program alumni. We also are implementing a peer mentoring component with recent LEAHP graduates, and are planning a mentor development program to create a pipeline of future mentors and leaders.

Physicians are inherently well-positioned to engage in health policy through their first-hand knowledge of the healthcare system and the patient experience, respect within their communities, research, and access to policymakers. Mentored, experiential training in health policy and advocacy can leverage this position and help move physicians from individual patient advocacy in the clinic to that of populations. The curriculum and experiences of the Leadership in Health Policy Program presented here can help to build the knowledge and amplify the scale of physicians engaged in health policy. We hope this program can be used as a model for other professional societies to build health policy and advocacy training and career development that can fit into daily lives of practicing physicians.

Contributors: None to report

Funding/Support: No external funding

Corresponding Author: Kelly A. Kyanko, MD, MHS; Department of Population Health, NYU Grossman School of Medicine, New York, NY, USA (e-mail: Kelly.Kyanko@nyulangone.org).

\section{Declarations:}

Conflict of Interest: The authors declare that they do not have a conflict of interest.

\section{REFERENCES}

1. Mou D, Sarma A, Sethi R, Merryman R. The state of health policy education in US medical schools. N Engl J Med. 2011;364(10):e19.

2. Patel MS, Davis MM, Lypson ML. Advancing medical education by teaching health policy. New England Journal of Medicine. 2011;364(8):695-697.

3. Medical professionalism in the new millennium: a physician charter. Annals of Internal Medicine. 2002; 136(3):243-246.

4. American Medical Association. AMA Declaration of Professional Responsibility. https://www.ama-assn.org/delivering-care/public-health/amadeclaration-professional-responsibility. Accessed October 4, 2021.

5. Earnest MA, Wong SL, Federico SG. Perspective: physician advocacy: what is it and how do we do it? Academic medicine. 2010;85(1):63-67.
6. Edgar L, Roberts S, Holmboe E. Milestones 2.0: a step forward. Journal of graduate medical education. 2018;10(3):367-369.

7. Accreditation Council for Graduate Medical Education. Milestones. https://www.acgme.org/what-we-do/accreditation/milestones/overview/. Accessed October 4, 2021.

8. Heiman HJ, Smith LL, McKool M, Mitchell DN, Roth Bayer C. Health policy training: a review of the literature. International journal of environmental research and public health. 2016;13(1):20.

9. Howell BA, Kristal RB, Whitmire LR, Gentry M, Rabin TL, Rosenbaum J. A systematic review of advocacy curricula in graduate medical education. Journal of general internal medicine. 2019;34(11):2592-2601.

10. McDonald M, Lavelle C, Wen M, Sherbino J, Hulme J. The state of health advocacy training in postgraduate medical education: a scoping review. Medical education. 2019;53(12):1209-1220.

11. Scott MD, McQueen S, Richardson L. Teaching health advocacy: a systematic review of educational interventions for postgraduate medical trainees. Academic Medicine. 2020;95(4):644-656.

12. Andrews $\mathbf{J}$, Jones $\mathbf{C}$, Tetrault $\mathbf{J}$, Coontz $\mathbf{K}$. Advocacy training for residents: insights from Tulane's internal medicine residency program. Academic Medicine. 2019;94(2):204-207.

13. Basu G, Pels RJ, Stark RL, Jain P, Bor DH, McCormick D. Training internal medicine residents in social medicine and research-based health advocacy: a novel, in-depth curriculum. Academic Medicine. 2017;92(4):515-520.

14. Greysen SR, Wassermann T, Payne P, Mullan F. Teaching health policy to residents-three-year experience with a multi-specialty curriculum. Journal of general internal medicine. 2009;24(12):1322-1326.

15. Strelnick AH, Swiderski D, Fornari A, et al. The residency program in social medicine of Montefiore Medical Center: 37 years of mission-driven, interdisciplinary training in primary care, population health, and social medicine. Academic Medicine. 2008;83(4):378-389.

16. Robert Wood Johnson Foundation Health Policy Fellows. https://www. healthpolicyfellows.org/. Accessed October 4, 2021.

17. American College of Physicians. ACP Health Policy Internship Program. https://www.acponline.org/advocacy/advocacy-in-action/acp-healthpolicy-internship-program. Accessed October 4, 2021.

18. Heiman HJ, Smith LL, Respress E, Bayer CR. Health policy training for health equity leaders. Ethnicity \& disease. 2019;29(Suppl 2):405.

19. Society of General Internal Medicine. SGIM LEAHP Leadership in Health Policy. https://www.sgim.org/communities/advocacy/leadership-inhealth-policy. Accessed October 4, 2021.

20. American Pediatric Association. Health Policy Scholars Program (HPSP). Accessed October 4, 2021.

21. Society of General Internal Medicine. About SGIM. https://www.sgim. org/about-us. Accessed October 4, 2021.

22. Schwartz M, Staiger T. New SGIM career development initiative: Leadership in Health Policy (LEAHP) program. SGIM Forum. 2016;39(10): 1, 10

23. Schwartz M, Staiger T. Leadership in Health Policy (LEAHP) program initiated at the 2017 annual meeting. SGIM Forum. 2017;40(8):8, 13.

24. Chen A, Cowart J, Riddle-Jones L, Candler S. 2020: the next LEAHP (Leadership in Health Policy) year. SGIM Forum. 2019;42(11):10, 15.

25. Cronbach LJ. Coefficient alpha and the internal structure of tests. psychometrika. 1951;16(3):297-334.

26. Fritz CO, Morris PE, Richler JJ. Effect size estimates: current use, calculations, and interpretation. Journal of experimental psychology: General. 2012;141(1):2.

27. Society of General Internal Medicine. SGIM TEACH Teaching Educators Across the Continuum of Healthcare. https://www.sgim.org/communities/education/sgim-teach-program. Accessed October 4, 2021.

28. Association of Chiefs and Leaders of General Internal Medicine. ACLGIM LEAD. https://www.sgim.org/aclgim-tools\%2D\%2Dprograms/lead. Accessed October 4, 2021

29. Bakken LL, Byars-Winston A, Wang M-f. Viewing clinical research career development through the lens of social cognitive career theory. Advances in Health Sciences Education. 2006;11(1):91-110.

Publisher's Note: Springer Nature remains neutral with regard to jurisdictional claims in published maps and institutional affiliations. 